\title{
Combustion Enhancement of Pulverized Coal with Targeted Oxygen-Enrichment in an Ironmaking Blast Furnace
}

\author{
Zhenfeng Zhou ${ }^{1, *}$, Ruihao Wang ${ }^{1}$, Qiujie Yi $^{1}$, Guang Wang ${ }^{2, *}$ and Chunyuan Ma ${ }^{3}$ \\ 1 College of Mechanical and Electronic Engineering, Shandong University of Science and Technology, \\ Qingdao 266590, China; w1320787264@163.com (R.W.); yiqiujie@163.com (Q.Y.) \\ 2 State Key Laboratory of Advanced Metallurgy, University of Science and Technology Beijing, \\ Beijing 100083, China \\ 3 National Engineering Laboratory of Coal-Fired Pollution Reduction, Shandong University, \\ Jinan 250061, China; sdetechym@163.com \\ * Correspondence: zhouzhenfeng@sdust.edu.cn (Z.Z.); wangguang@ustb.edu.cn (G.W.); \\ Tel.: +86-0532-86057685 (Z.Z.); +86-010-62332880 (G.W.)
}

check for updates

Citation: Zhou, Z.; Wang, R.; Yi, Q.; Wang, G.; Ma, C. Combustion Enhancement of Pulverized Coal with Targeted Oxygen-Enrichment in an Ironmaking Blast Furnace. Processes 2021, 9, 440. https://doi.org/ $10.3390 /$ pr 9030440

Academic Editor: Fabrizio Scala

Received: 25 January 2021

Accepted: 24 February 2021

Published: 28 February 2021

Publisher's Note: MDPI stays neutral with regard to jurisdictional claims in published maps and institutional affiliations.

Copyright: (c) 2021 by the authors. Licensee MDPI, Basel, Switzerland. This article is an open access article distributed under the terms and conditions of the Creative Commons Attribution (CC BY) license (https:// creativecommons.org/licenses/by/ $4.0 /)$.

\begin{abstract}
In this study, a targeted oxygen-enrichment technology was proposed to enhance coal combustion in an ironmaking blast furnace. The coal flow and combustion characteristics under targeted oxygen-enrichment were investigated using the computational fluid dynamics (CFD) method. The results showed that oxygen utilization and coal burnout were significantly increased under targeted oxygen-enrichment. The coal burnout at $24 \% \mathrm{O}_{2}$ concentration was $86.29 \%$, which was the maximum and indicated an increase of $13.13 \%$. However, the cooling effect of room-temperature oxygen had some adverse effects on coal combustion. Given this, the effect of coal particle temperature on coal combustion was investigated based on targeted oxygen-enrichment. The coal combustion process was further enhanced. The coal burnout at a $600 \mathrm{~K}$ particle temperature and $25 \%$ oxygen concentration was $91.12 \%$ and had an increase of $17.96 \%$, which was the maximum.
\end{abstract}

Keywords: ironmaking blast furnace; targeted oxygen-enrichment; coal particles temperature; coal burnout

\section{Introduction}

The ironmaking blast furnace is the main facility for hot metal production and more than $94 \%$ of pig iron is produced by it due to its higher productivity and competitive production costs [1-5]. The coke involved in this process must be used during the blast furnace production process and about $350 \mathrm{~kg}$ of coke will be consumed for a tonne of hot metal. However, metallurgical coal resources are becoming increasingly scarce, prices are increasing, and the production cost of a blast furnace is increasing. Furthermore, the coking process produces much pollution [6]. Therefore, reducing the use of coke is the key to solving these problems.

The injection of pulverized coal through tuyeres in the lower part of the blast furnace can effectively reduce the use of coke. However, an adverse effect is produced with an increase of the pulverized coal injection ratio. Mostly, this will lead to a lower carbon utilization efficiency and higher unburnt char due to the complex transfer processes inside the furnace $[7,8]$. Therefore, increasing the burnout of pulverized coal in the raceway region is key to further increasing the pulverized coal injection ratio [9]. Shen et al. [10] investigated the effect of oxygen concentration in the hot blast on coal burnout in the blast furnace. When the oxygen concentration increased from $21 \%$ to $25 \%$, the coal burnout had an increase of only 5\%. Liu et al. [11] investigated the effect of hot blast temperature on coal combustion. When the blast temperature increased from 1150 to $1250{ }^{\circ} \mathrm{C}$, the coal burnout had an increase of only 5\%. Chen et al. [12,13] investigated the coal combustion under oxygen enrichment technology with a coaxial oxygen-coal lance. The coal burnout was 
found to have a slight change. The coal burnout is difficult to increase further by traditional methods. Consequently, there is a need to develop a new blast furnace pulverized coal injection technology. Therefore, a targeted oxygen-enrichment technology was proposed.

The environment state and reactions in the ironmaking blast furnace are very complex, and the temperature in the raceway region is very high. Therefore, it is difficult to obtain the combustion characteristics of pulverized coal in a practical blast furnace directly [14]. Fortunately, computational fluid dynamics (CFD) provide an effective method for the investigation of pulverized coal injection [12,15]. Shen et al. [7,16,17] investigated the coal flow and combustion characteristics in the ironmaking blast furnace using the CFD method. Du et al. $[14,18]$ investigated the effect of lance configurations on coal combustion using the CFD method. The reliability and superiority of CFD in understanding pulverized coal combustion have been fully proven [10,18-21].

In this study, the coal combustion process in an ironmaking blast furnace under targeted oxygen-enrichment was investigated using CFD. The coal burnout had an obvious increase under targeted oxygen-enrichment. Furthermore, the effect of coal particles temperature based on targeted oxygen-enrichment was investigated. The coal burnout was found to be further increased. The present study could provide useful insights into the development of pulverized coal injection technology with oxygen enrichment on the ironmaking blast furnace.

\section{Geometry and Operating Condition}

The study was based on a blast furnace of $120 \mathrm{~m}^{3}$ because a test oxygen blast furnace of $120 \mathrm{~m}^{3}$ will be designed and built based on it. The raceway depth of the blast furnace was about $700 \mathrm{~mm}$. Previous studies showed most pulverized coal particles in the raceway region flow around the tuyere centerline due to having a fast blast speed, and the burnout at the end of the raceway represents that of the overall raceway [19]. Therefore, the raceway was simply designed as a gradually expanding tube following others [10]. The geometric details of the models are shown in Figure 1a,b. Furthermore, the diameters of coal and oxygen lances were $15 \mathrm{~mm}$ and $20 \mathrm{~mm}$, respectively. The model geometries simulated include the lances, blowpipe, tuyere, and raceway of a blast furnace. For the base case, the coal lance tip was located on the tuyere centerline, as shown in Figure 1a. For the targeted oxygen-enrichment case, the oxygen lance tip was located on the tuyere centerline and the coal lance tip was above the tuyere centerline, as shown in Figure 1b. In this model, the hybrid mesh was used, as shown in Figure 1c,d.

Furthermore, the grid-independent has been checked. Three different numbers of meshes were used for the mesh independence study. The simulation results under three different numbers of meshes are shown in Table 1. Table 1a shows the coal burnout at $21 \% \mathrm{O}_{2}$ using the base case model. Table $1 \mathrm{~b}$ shows the coal burnout at $22 \% \mathrm{O}_{2}$ using the targeted oxygen-enrichment model. The results indicate that the mesh is proper.

The boundary conditions and operating conditions of the blast furnace are summarized in Table 2. The properties of pulverized coal used in this model were shown in our other study [22].

Table 1. The coal burnout of different numbers of meshes: (a) Base case; (b) targeted oxygen-enrichment.

(a)

\begin{tabular}{cccc}
\hline Number of mesh & 171,014 & 260,414 & 361,322 \\
\hline Burnout & 73.28 & 73.16 & 73.24 \\
\hline Number of mesh & & $($ b) & \\
\hline Burnout & 254,021 & 403,621 & 577,334 \\
\hline
\end{tabular}




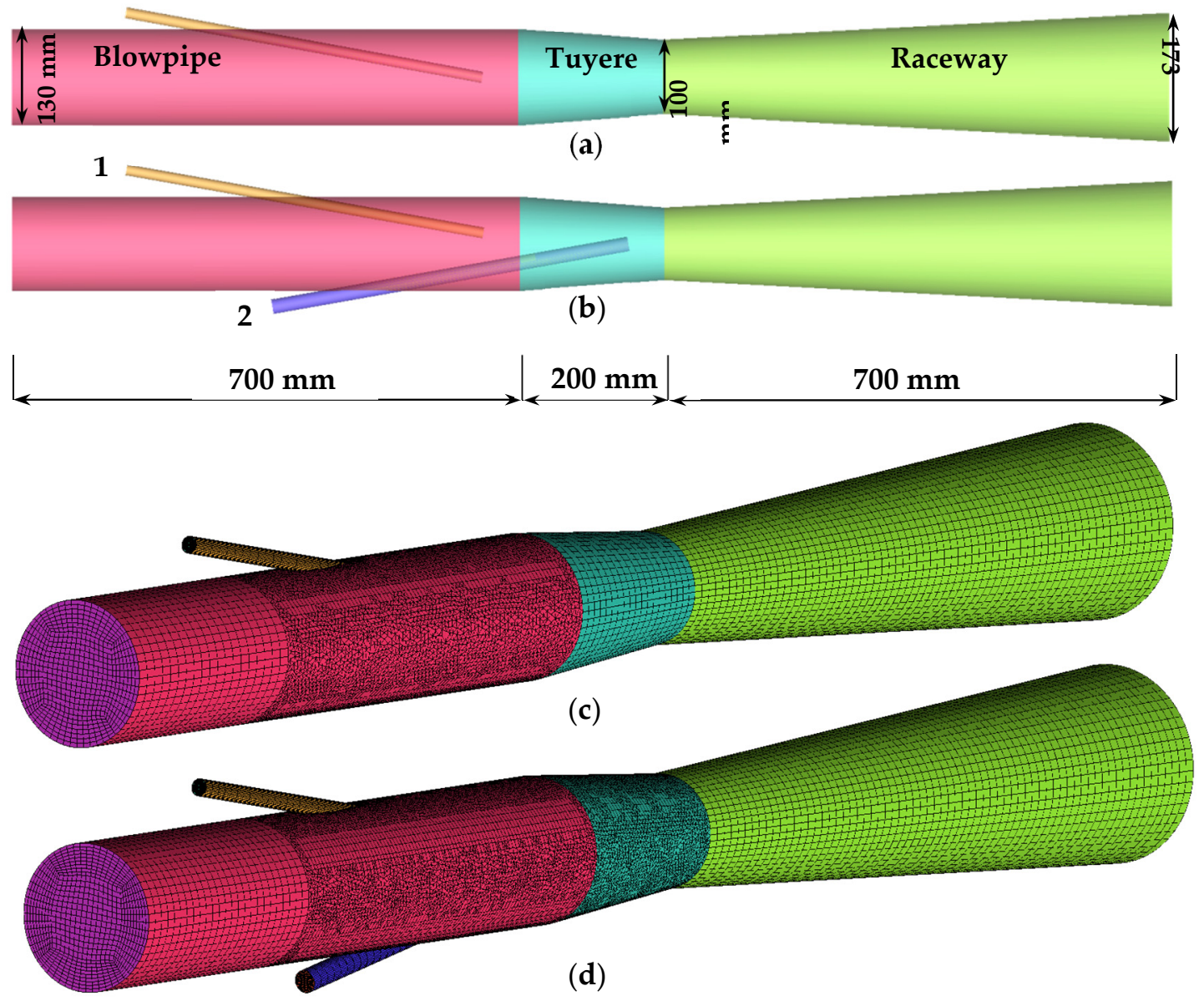

1. Coal lance; 2. Oxygen lance

Figure 1. Geometry and mesh: (a), (c) base case; and (b), (d) targeted oxygen enrichment.

Table 2. Boundary conditions and operating conditions.

\begin{tabular}{cc}
\hline Hot blast & \\
\hline Temperature, $\mathrm{K}$ & 1473 \\
\hline Volume, $\mathrm{Nm}^{3} / \mathrm{t} \cdot \mathrm{HM}$ & 1127 \\
\hline Velocity, $\mathrm{m} / \mathrm{s}$ & 93.05 \\
\hline Oxygen content, $\%$ & 21 \\
\hline Coal & 0.091 \\
\hline Coal rate, $\mathrm{kg} / \mathrm{s}$ & 150 \\
\hline Coal ratio, $\mathrm{kg} / \mathrm{t} \cdot \mathrm{HM}$ & 298 \\
\hline Oxygen & $1,2,3,4,5,6$ \\
\hline Temperature, $\mathrm{K}$ & $8,16,24,32,40,48$ \\
\hline Content, $\%$ & \\
\hline Velocity, $\mathrm{m} / \mathrm{s}$ & \\
\hline
\end{tabular}

\section{Model Description}

The gas-particle flow and coal combustion in the tuyere and raceway region were calculated based on the framework of the software package ANSYS-FLUENT (Qingdao, China). Details of the model formulation describing the gas and particle phases were provided previously $[15,22,23]$. An outline was provided below. 


\subsection{Basic Equations}

The governing equations for gas and particle phases have been fully described in other studies $[15,22,23]$. Governing equations solved for the gas phase included mass, momentum, turbulence kinetic energy, turbulence dissipation rate, enthalpy, and some species mass fractions, as shown in Table 3a. The pulverized coal particles were treated as a discrete phase, modeled using the Lagrangian method, where the trajectories of the discrete particles were determined by integrating Newton's second law of motion. Governing equations solved for the particle phase included mass, momentum, and energy of particles with the gas phase, as shown in Table $3 b$.

Table 3. Governing equations: (a) governing equations for the gas phase; and (b) governing equations for the particle phase.

(a)

\begin{tabular}{|c|c|}
\hline Mass & $\nabla(\rho U)=\sum_{n_{p}} \dot{m}$ \\
\hline Momentum & $\nabla(\rho U U)-\nabla\left[\left(\mu+\mu_{t}\right)\left(\nabla U+(\nabla U)^{T}\right)\right]=-\nabla\left(P+\frac{2}{3} \rho k\right)+\sum_{n_{P}} f_{D}$ \\
\hline Energy & $\nabla\left[\rho U H-\left(\frac{\lambda}{C_{P}}+\frac{\mu_{t}}{\sigma_{H}}\right)\right]=\sum_{n_{P}} q$ \\
\hline Gas species & $\nabla\left[\rho U Y_{i}-\left(\Gamma_{i}+\frac{\mu_{t}}{\sigma_{Y i}}\right)\right]=W_{i}$ \\
\hline Turbulent kinetic energy & $\nabla\left[\rho U k-\left(\mu+\frac{\mu_{t}}{\sigma_{k}}\right) \nabla k\right]=P_{k}-\rho \varepsilon$ \\
\hline Turbulent dissipation rate & $\nabla\left[\rho U \varepsilon-\left(\mu+\frac{\mu_{t}}{\sigma_{\varepsilon}}\right) \nabla \varepsilon\right]=\frac{\varepsilon}{k}\left(C_{1} P_{k}-C_{2} \rho \varepsilon\right)$ \\
\hline \multicolumn{2}{|r|}{ (b) } \\
\hline Mass & $\frac{d m_{p}}{d t}=-\dot{m}$ \\
\hline Momentum & $\begin{array}{l}m_{p} \frac{d u_{p}}{d t}=-f_{D} \\
-f_{D}=\frac{1}{8} \pi d_{p}^{2} \rho C_{D}\left|U-U_{p}\right|\left(U-U_{p}\right)\end{array}$ \\
\hline Energy & $\begin{array}{l}m_{p} C_{p} \frac{d T_{p}}{d t}=-q \\
\pi d_{p} \lambda N_{\mu}\left(T_{g}-T_{p}\right)+\sum \frac{d m_{p}}{d t} H_{r e a c}+A_{p} \varepsilon_{p}\left(\pi I-\sigma_{B} T_{p}^{4}\right)\end{array}$ \\
\hline
\end{tabular}

\subsection{Reaction Process}

To further illustrate the influence mechanism of the oxygen stream, the oxygen in the hot blast and added oxygen were represented using $\mathrm{O}_{2}$ and ${ }^{18} \mathrm{O}_{2}$ symbols during the simulation process. The schematic diagram of $\mathrm{O}_{2}$ and ${ }^{18} \mathrm{O}_{2}$ flow is shown in Figure 2. All properties of $\mathrm{O}_{2}$ and ${ }^{18} \mathrm{O}_{2}$ were the same in addition to symbols. Therefore, the reactions of coal and their reaction rates' expression are listed in Table 4.

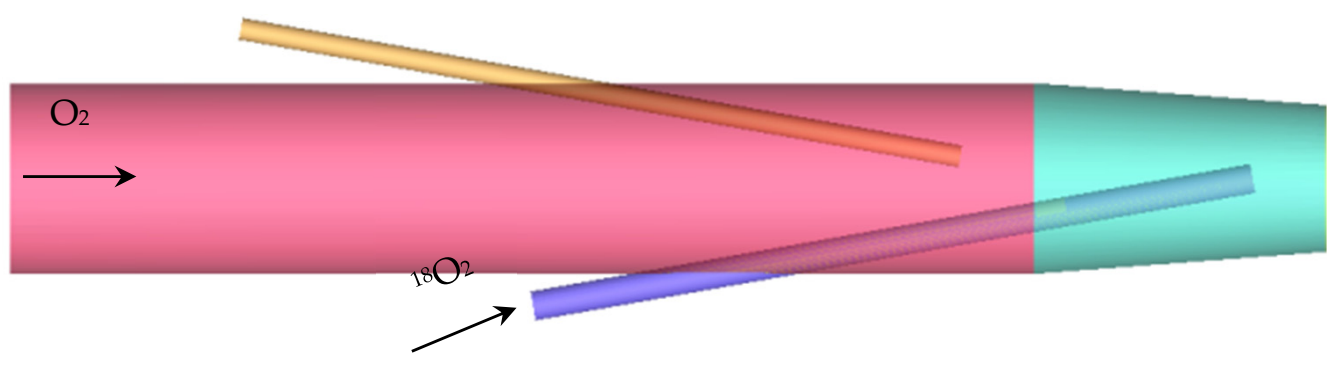

Figure 2. Schematic diagram of $\mathrm{O}_{2}$ and ${ }^{18} \mathrm{O}_{2}$. 
Table 4. Chemical reactions of coal and reaction kinetics [16,17].

\begin{tabular}{|c|c|c|c|}
\hline Reacions & & Reaction Rate & Reaction Kinetics \\
\hline Raw coal $\rightarrow \mathrm{VM}+$ Char & $\mathbf{R}_{\mathbf{1}}$ & $\begin{array}{c}\text { Raw Coal }\left\{\begin{array}{l}\stackrel{K_{1}}{\rightarrow} \alpha_{1} V M_{1}+\left(1-\alpha_{1}\right) \text { Char } \\
\stackrel{K_{2}}{\rightarrow} \alpha_{2} V M_{2}+\left(1-\alpha_{2}\right) \text { Char }\end{array}\right. \\
\frac{d V M}{d t}=\left(\alpha_{1} k_{1}+\alpha_{2} k_{2}\right) C_{0} \\
k=A \exp \left(-E / R T_{p}\right)\end{array}$ & $\begin{array}{c}A_{1}=3.7 \times 10^{5} \mathrm{~s}^{-1}, E_{1}=149.6 \mathrm{~kJ} \cdot \mathrm{mol}^{-1} \\
A_{2}=1.46 \times 10^{13} \mathrm{~s}^{-1}, E_{2}=251 \mathrm{~kJ} \cdot \mathrm{mol}^{-1} \\
\alpha_{1}=V M(\text { daf }) \alpha_{2}=1.25 \alpha_{1}^{2}+0.92 \alpha_{1}\end{array}$ \\
\hline $\mathrm{VM}+\mathrm{O}_{2} \rightarrow \mathrm{CO}+\mathrm{H}_{2} \mathrm{O}+\mathrm{N}_{2}$ & $\mathbf{R}_{\mathbf{2}}$ & & \\
\hline $\mathrm{CO}+0.5 \mathrm{O}_{2}=\mathrm{CO}_{2}$ & $\mathbf{R}_{3}$ & & \\
\hline $\mathrm{H}_{2}+0.5 \mathrm{O}_{2}=\mathrm{H}_{2} \mathrm{O}$ & $\mathbf{R}_{4}$ & & \\
\hline $\mathrm{VM}+{ }^{18} \mathrm{O}_{2} \rightarrow \mathrm{C}^{18} \mathrm{O}+\mathrm{H}_{2}{ }^{18} \mathrm{O}+\mathrm{N}_{2}$ & $\mathbf{R}_{5}$ & $r:=C_{1} \frac{\varepsilon}{m} \min (\underline{[i]})$ & \\
\hline $\begin{aligned} \mathrm{C}^{18} \mathrm{O}+0.5^{18} \mathrm{O}_{2} & =\mathrm{C}^{18} \mathrm{O}_{2} \mathrm{R}_{6} \\
\mathrm{C}^{18} \mathrm{O}+0.5 \mathrm{O}_{2} & =\mathrm{C}^{18} \mathrm{OO}\end{aligned}$ & $\begin{array}{l}\mathbf{R}_{6} \\
\mathbf{R}_{7}\end{array}$ & $r_{i}=C_{A} \frac{\varepsilon}{k} \min \left(\frac{\frac{1 i j}{v_{t}^{\prime}}}{v_{t}}\right)$ & \\
\hline $\mathrm{CO}+0.5^{18} \mathrm{O}_{2}=\mathrm{C}^{18} \mathrm{OO}$ & $\mathbf{R}_{8}$ & & \\
\hline $\mathrm{H}_{2}+0.5^{18} \mathrm{O}_{2}=\mathrm{H}_{2}{ }^{18} \mathrm{O}$ & $\mathbf{R}_{9}$ & & \\
\hline$\Phi$ char $+\mathrm{O}_{2} \rightarrow 2(\Phi-1) \mathrm{CO}+(2-\Phi) \mathrm{CO}_{2}$ & $\mathbf{R}_{\mathbf{1 0}}$ & $\frac{d m_{c}}{d t}=-\frac{3 \phi}{1-e} \frac{M_{C}}{M_{\mathrm{O}_{2}}} \frac{\rho_{\infty}}{\rho_{c}}\left(k_{1}^{-1}+\left(k_{2}+k_{3}\right)^{-1}\right)^{-1} m_{C}$ & $A_{1}=3.7 \times 10^{5} \mathrm{~s}^{-1}, E_{1}=18,000 \mathrm{~K}$ \\
\hline$\Phi$ char $+{ }^{18} \mathrm{O}_{2} \rightarrow 2(\Phi-1) \mathrm{C}^{18} \mathrm{O}+(2-\Phi) \mathrm{C}^{18} \mathrm{O}_{2}$ & $\mathbf{R}_{11}$ & $\frac{2(\phi-1)}{2-\phi}=A_{s} \exp \left(-\frac{T_{s}}{T_{p}}\right)$ & $A_{2}=1.46 \times 10^{13} \mathrm{~s}^{-1}, E_{2}=30,189 \mathrm{~K}$ \\
\hline Фchar $+\mathrm{C}^{18} \mathrm{O}_{2} \rightarrow 2 \mathrm{C}^{18} \mathrm{O}$ & $\mathbf{R}_{12}$ & $k_{1}=\frac{D}{r_{p}^{2}}, D=\frac{D_{r e f}}{\rho}\left(\frac{T_{p}+T_{g}}{2 T_{r e f}}\right)^{\alpha}, k_{2}=(1-e) \frac{k_{c}}{r_{p}}$ & $\begin{array}{c}C_{A}=4.0 A_{c}=14 \mathrm{~m} \cdot \mathrm{s}^{-1} \cdot \mathrm{K}^{-1} \\
T_{c}=21,580 \mathrm{~K}\end{array}$ \\
\hline$\Phi$ char $+\mathrm{C}^{18} \mathrm{OO} \rightarrow \mathrm{C}^{18} \mathrm{O}+\mathrm{CO}$ & $\mathbf{R}_{\mathbf{1 3}}$ & $k_{3}=k_{c} T_{p}(\beta \operatorname{coth} \beta-1) / \beta^{2} \alpha$ & $A_{c}=20,230 \mathrm{~m} \cdot \mathrm{s}^{-1} \cdot \mathrm{K}^{-1}, T_{c}=39,743 \mathrm{~K}$ \\
\hline$\Phi$ char $+\mathrm{H}_{2}{ }^{18} \mathrm{O} \rightarrow \mathrm{C}^{18} \mathrm{O}+\mathrm{H}_{2}$ & $\mathbf{R}_{14}$ & $k_{c}=A_{c} T_{p} \exp \left(-T_{c} / T_{p}\right), \beta=R\left(\frac{k_{c}}{D_{p} e a}\right)^{0.5}$ & $A_{c}=606.9 \mathrm{~m} \cdot \mathrm{s}^{-1} \cdot \mathrm{K}^{-1}, T_{c}=32,406 \mathrm{~K}$ \\
\hline
\end{tabular}

\section{Results and Discussion}

\subsection{Model Validation}

Before applying this model to simulate the coal combustion process in a real blast furnace, the validation had been conducted using a lab-scale drop tube furnace (DTF), as shown in Figure 3. The DTF is $1850 \mathrm{~mm}$ high, and the isothermal zone is $1400 \mathrm{~mm}$ long. The coal feeding rate was approximately $0.7 \mathrm{~g} / \mathrm{min}$. The effect of oxygen concentration on coal burnout at $1173 \mathrm{~K}$ was investigated using the DTF and CFD model. Figure $4 \mathrm{a}$ shows the effect of oxygen concentration on coal burnout, which is the average of three experiments. The result shows a reasonable agreement between the values given by the DTF and CFD models. Figure $4 \mathrm{~b}$ shows the change of $\mathrm{CO}$ concentration at the outlet under different oxygen concentration. The experimental data are in good agreement with the theoretical data. The simulation results have some discrepancies against the experimental data. This is because some experimental conditions were simplified in the simulation process. Furthermore, some factors affects the experimental results, but the simulation process is less affected.

Furthermore, the effect of oxygen concentration on coal burnout under simulated blast furnace conditions was investigated by CFD model, as shown in Figure 5 . When the oxygen concentration had a $1 \%$ increase, the coal burnout had about a $1 \%$ increase. The values show a reasonable agreement with that of Shen and Liu $[10,11]$. The comparisons indicate that the simulated model is reliable.

\subsection{Concept of Targeted Oxygen-Enrichment}

Figure 6 shows the effect of oxygen concentration in hot blast on final coal burnout at the raceway outlet. The coal burnout slightly increased with increase in oxygen content. When the oxygen concentration increased from $21 \%$ to $27 \%$, the coal burnout had an increase of only $6.15 \%$. This is in good agreement with the result of Shen [10]. For the blast furnace, $1127 \mathrm{Nm}^{3}$ hot blast and $150 \mathrm{~kg}$ of pulverized coal would be consumed for producing one ton hot metal. In theory, the coal burnout would be increased by $11.39 \%$ under $1 \%$ oxygen enrichment. That showed much oxygen was not utilized by coal particles and the oxygen utilization was about only $10 \%$. If all oxygen could be used by coal particles, the coal burnout would significantly increase, even at lower oxygen enrichment. 


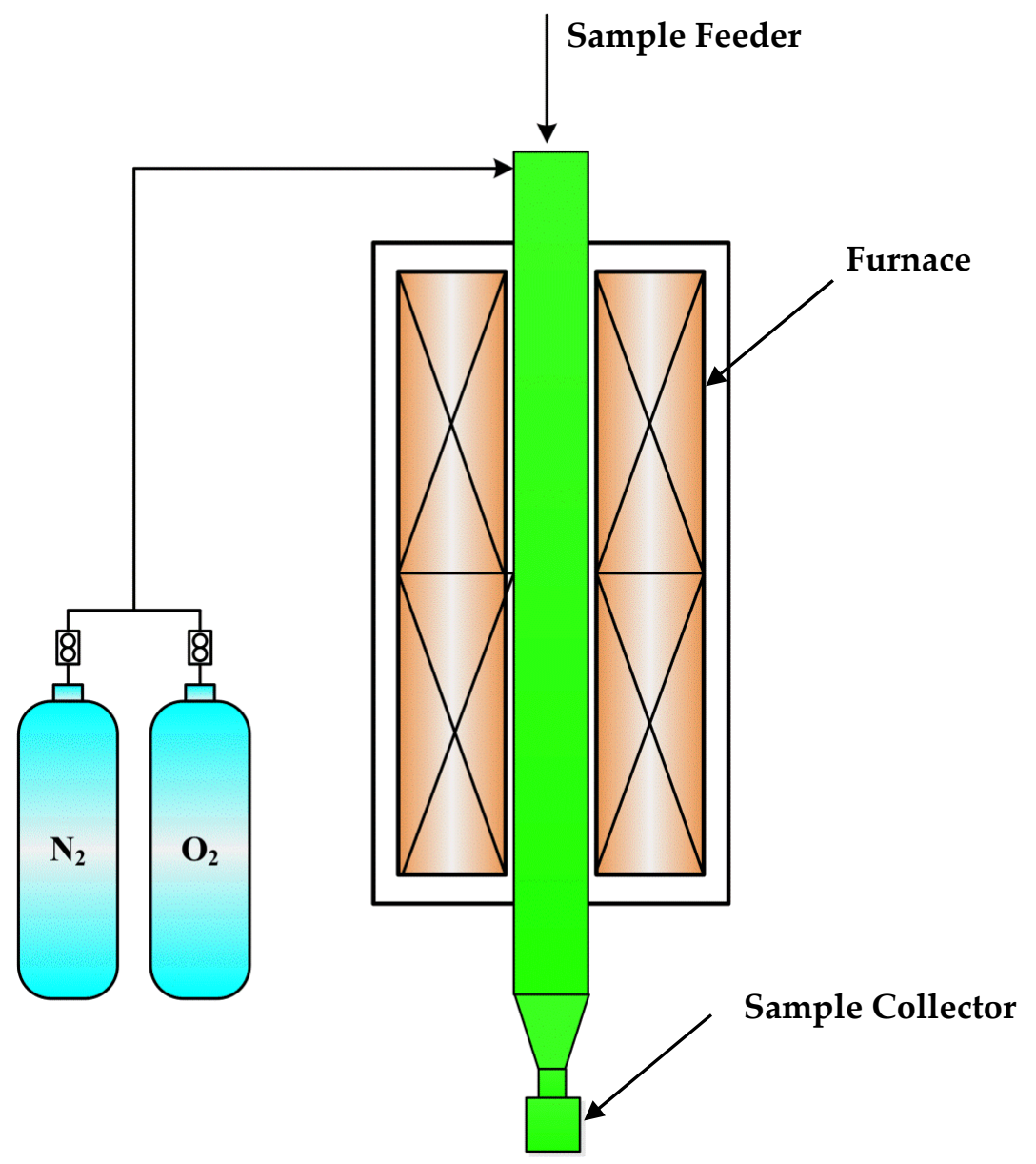

Figure 3. Schematic diagram of the drop-tube furnace system.
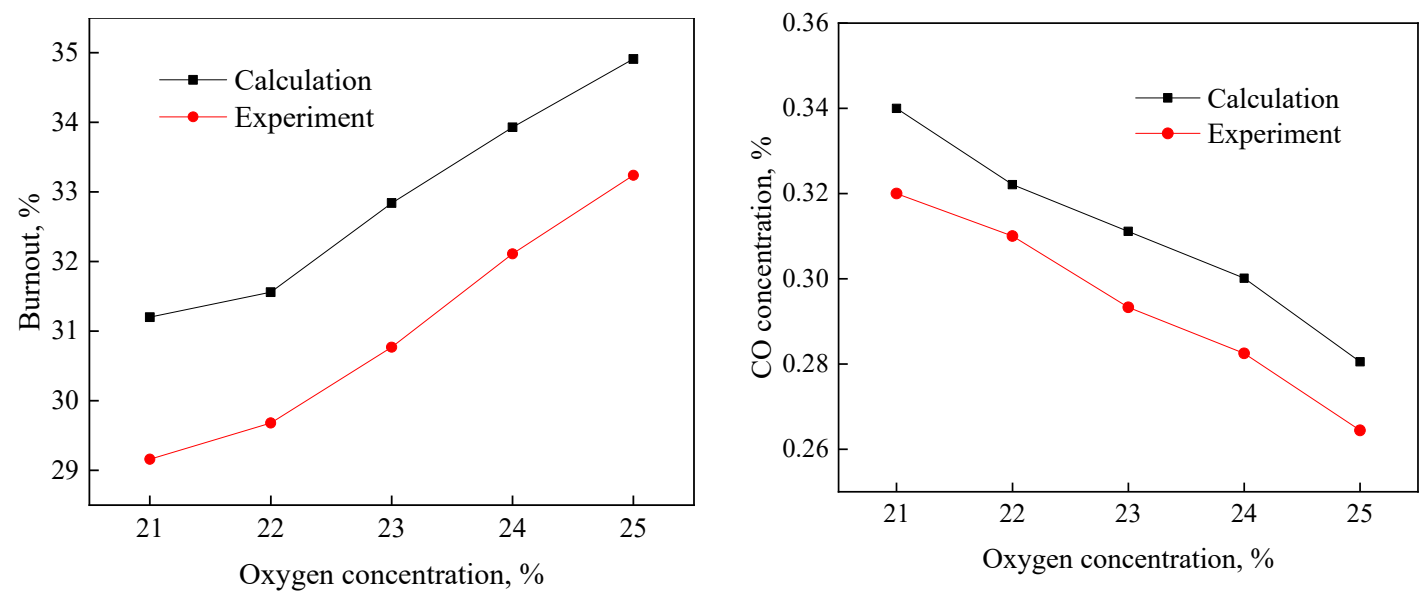

Figure 4. Effect of oxygen concentration on: coal burnout (left); CO concentration (right).

To further understand the reasons causing the aforementioned phenomena, the coal burnout distribution at the raceway outlet was analyzed, as shown in Figure 7a. A significant amount of coal particles with lower burnout were concentrated in the central area of the coal particles cluster, where no oxygen could be found (Figure $7 \mathrm{~b}$ ). The phenomenon was also shown in our previous study [24]. That meant a large number of coal particles could not completely combust due to the lack of oxygen.

The coal burnout would increase only by increasing the oxygen concentration in the lower-burnout area. Given this, the concept of targeted oxygen-enrichment was proposed, 
and the oxygen was enriched into the lower-burnout region, as shown in Figure 7c. A targeted oxygen-enrichment method was proposed, in which the room-temperature oxygen was injected by the oxygen lance, as shown in Figure 1b. The oxygen concentration in the hot blast was $21 \%$, and the other oxygen was added by an oxygen lance.

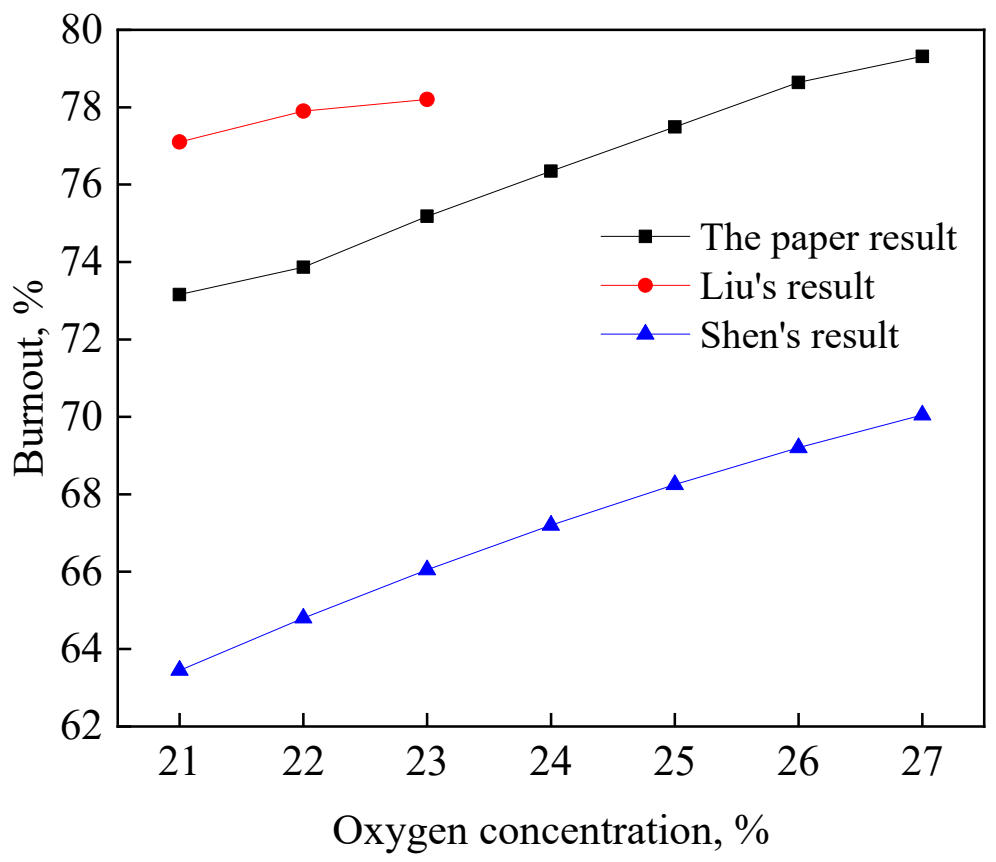

Figure 5. Comparison of simulated results with that of Shen and Liu.

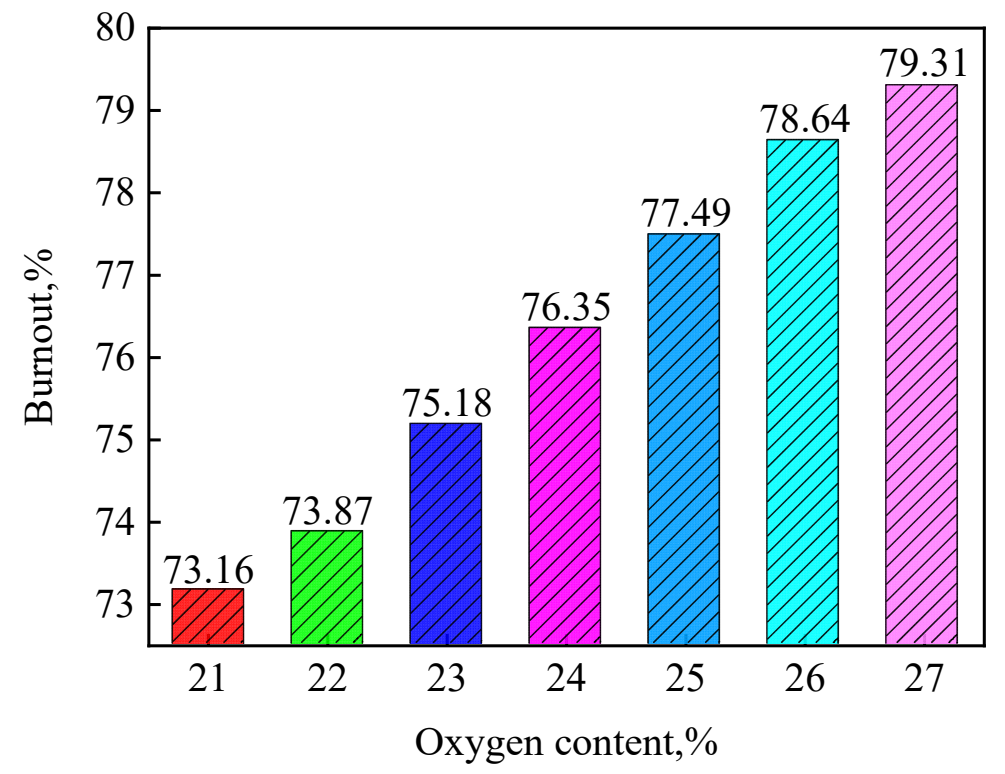

Figure 6. Effect of oxygen concentration in hot blast on final coal burnout. 


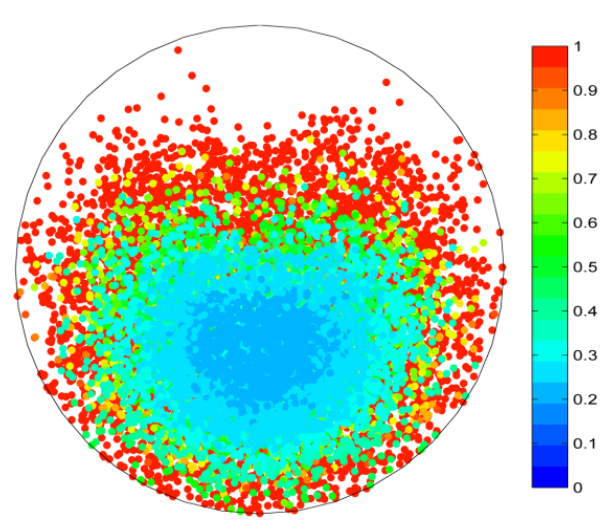

(a)

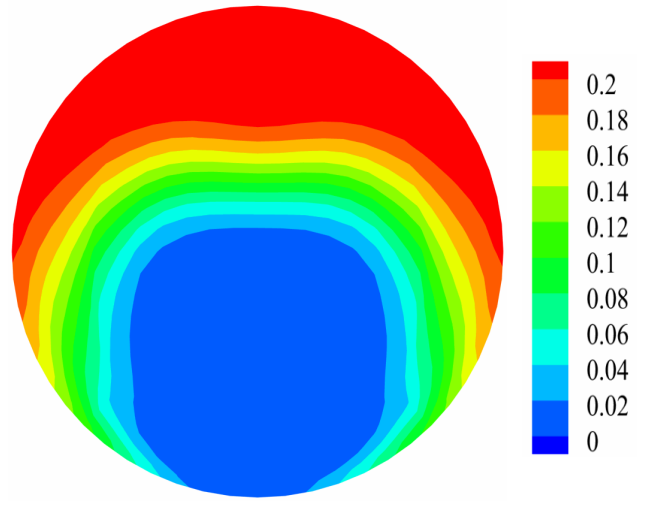

(b)

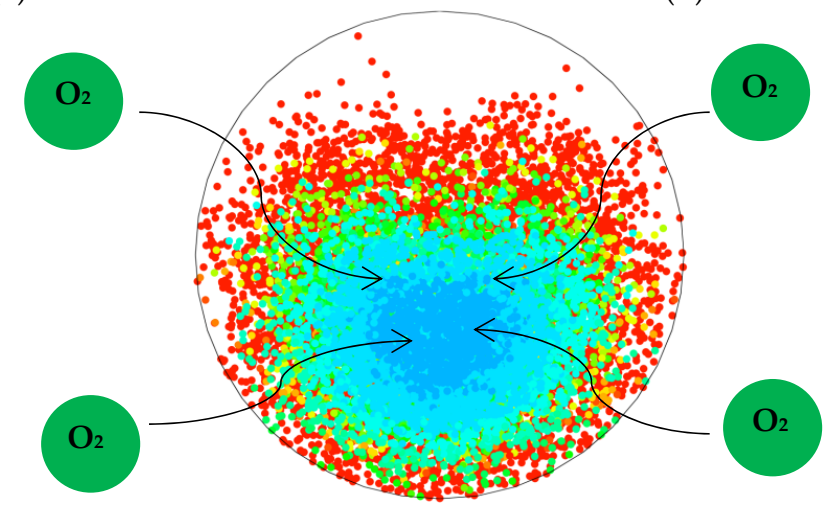

(c)

Figure 7. Raceway outlet: (a) coal burnout distribution; (b) oxygen distribution; (c) concept of targeted oxygen enrichment.

\subsection{Coal Combustion Characteristics under Targeted Oxygen-Enrichment}

Figure 8a shows the effect of oxygen content on final coal burnout under targeted oxygen-enrichment. When oxygen content was $22 \%$, the coal burnout was $83.75 \%$, an increase of $10.59 \%$, which was close to the theoretical increase of $11.39 \%$. However, the coal burnout slowly changed as more oxygen was added. The coal burnout was $86.29 \%$ at $24 \%$ $\mathrm{O}_{2}$ content, an increase of $13.13 \%$, which was the maximum. Then the coal burnout slowly decreased as more oxygen was added.

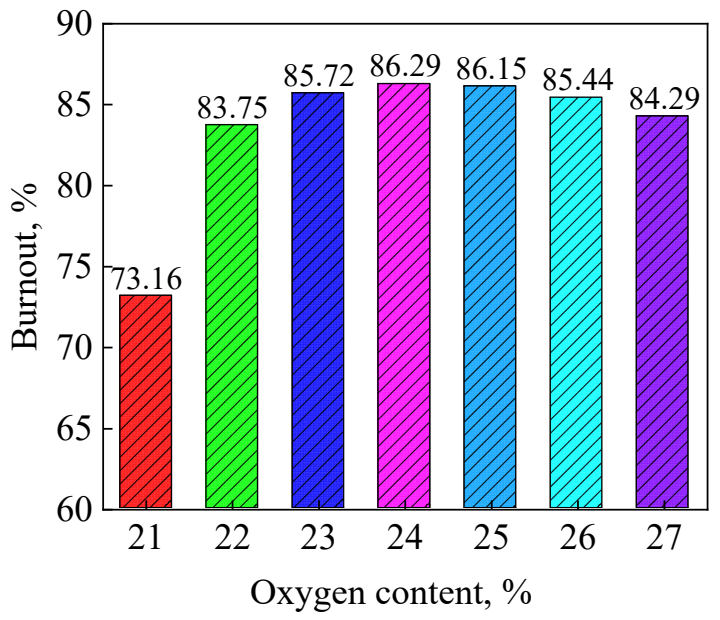

(a)

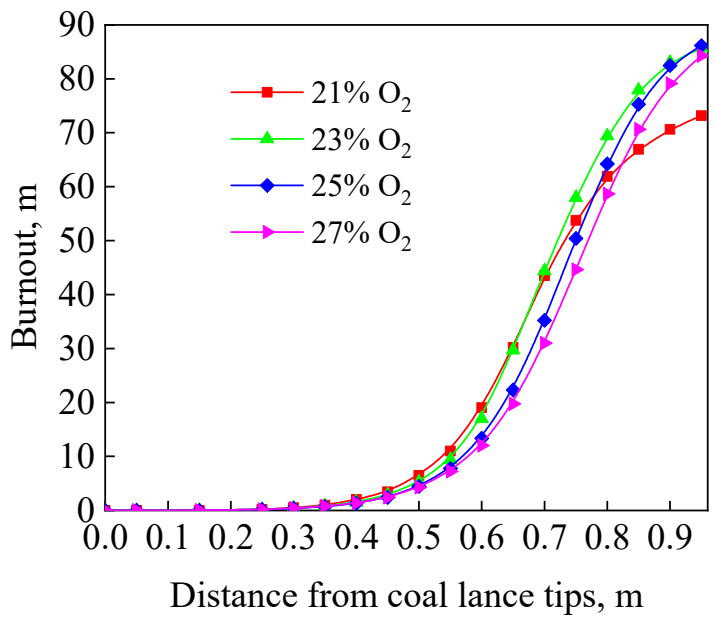

(b)

Figure 8. Effect of oxygen content under targeted oxygen enrichment: (a) final burnout; (b) combustion process. 
To further reveal the reasons causing the aforementioned phenomena, the change of coal burnout across the whole combustion process was investigated, as shown in Figure 8b. The coal combustion process was delayed under the effect of room-temperature oxygen, which became more obvious as more oxygen was added. Du et al. [12]. also found the same phenomenon. Significant devolatilization just starts around $600 \mathrm{~K}$ [25]. The room-temperature oxygen first competed for limited heat with coal particles, and then the combustion distance of char would be shortened. Some coal particles would leave the raceway region without complete combustion even at rich oxygen concentration.

Figure 9 shows the distribution of coal burnout under targeted oxygen enrichment. It showed that the higher-burnout area moved toward the center of the coal plume. The oxygen stream flowed into the original lower-burnout region, where the coal particles rapidly burnt. The higher-burnout area became larger with an increase in oxygen enrichment. Furthermore, the coal particles were more dispersed under the effect of oxygen stream, which was helpful to coal combustion. The factors caused a higher coal burnout under targeted oxygen-enrichment.

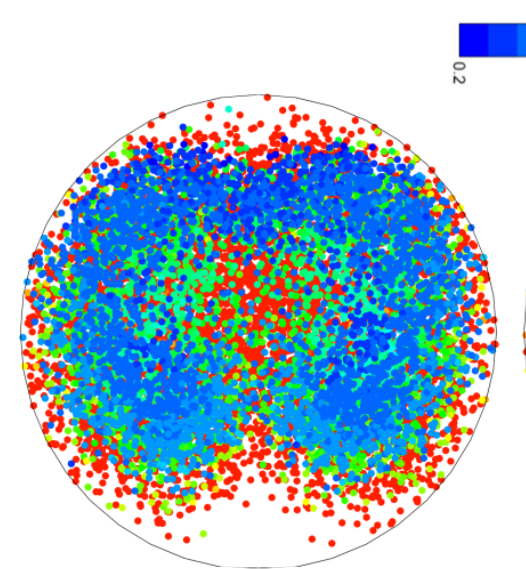

(a) $23 \% \mathrm{O}_{2}$

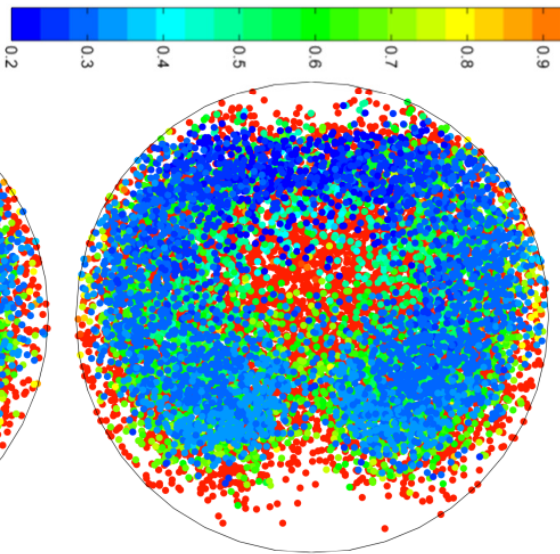

(b) $25 \% \mathrm{O}_{2}$

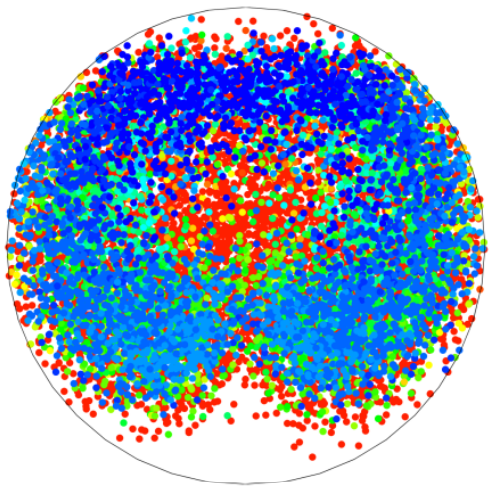

(c) $27 \% \mathrm{O}_{2}$

Figure 9. Coal particles combustion characteristics under targeted oxygen-enrichment.

However, the new lower-burnout area occurred under targeted oxygen-enrichment. Figure 10 showed the coal particles that burnout was less than 0.5 , which was described as targeted particles. For the base case, the targeted particles were mainly concentrated in the center region of the coal plume. However, the targeted particles were more dispersed under targeted oxygen enrichment, which was distributed around the coal plume. This was mainly because the oxygen stream flowed into the center of the coal plume, where the coal particles rapidly burnt and dispersed toward the around region. The coal burnout of targeted oxygen-enrichment was higher than that of the base case, but decreased with an increase in oxygen concentration. The oxygen has exceeded that the coal combustion needed, and the room-temperature oxygen had some adverse effect on coal combustion. The benefits outweighed the injuries with an increase in oxygen content. Furthermore, it was more difficult for oxygen to approach the newly targeted area. This further explained the results shown in Figure 8.

Figure 11 shows the concentration change of several typical elements. The amount of $\mathrm{N}_{2}$ kept the same, thus the concentration ratio of the element with $\mathrm{N}_{2}$ was used to represents its concentration change. The $\mathrm{CO}$ concentration decreased with an increase in oxygen enrichment. The concentration of $\mathrm{C}^{18} \mathrm{O},{ }^{18} \mathrm{O}_{2}$, and $\mathrm{C}^{18} \mathrm{OO}$ increased with the increase in oxygen concentration. The increase of $\mathrm{C}^{18} \mathrm{O}$ showed more carbon reacts with ${ }^{18} \mathrm{O}_{2}$. The increase of $\mathrm{C}^{18} \mathrm{OO}$ indicated that more $\mathrm{CO}$ reacted with ${ }^{18} \mathrm{O}_{2}$. When oxygen concentration increased from $22 \%$ to $27 \%$, the $\mathrm{C}^{18} \mathrm{OO}$ concentration had an increase of $0.75 \%$, while the CO concentration was decreased by $3.01 \%$. This indicated that the decrease 
of $\mathrm{CO}$ concentration was mainly caused by the reduction of carbon reacting with $\mathrm{O}_{2}$. The carbon that reacted with ${ }^{18} \mathrm{O}_{2}$ increased, but that reacted with $\mathrm{O}_{2}$ decreased. This resulted in a slight increase in coal burnout with an increase in oxygen content. Figure 11D shows the conversion ratio of ${ }^{18} \mathrm{O}_{2}$ decreases with an increase in oxygen enrichment. The conversion ratio of ${ }^{18} \mathrm{O}_{2}$ was $88.58 \%$ at $1 \%$ oxygen enrichment, while the value was only $48.43 \%$ at $6 \%$ oxygen enrichment. It indicated more oxygen was not utilized by coal particles with an increase in oxygen enrichment. This further explained the result in Figure 8a.

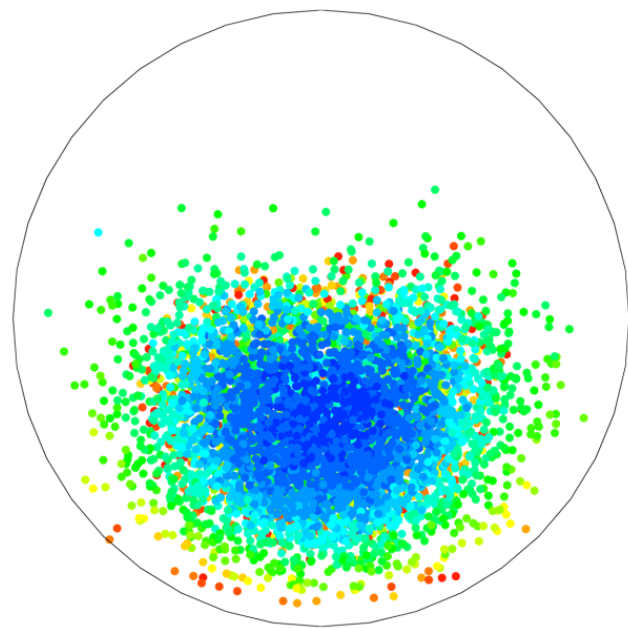

(a) $21 \% \mathrm{O}_{2}$

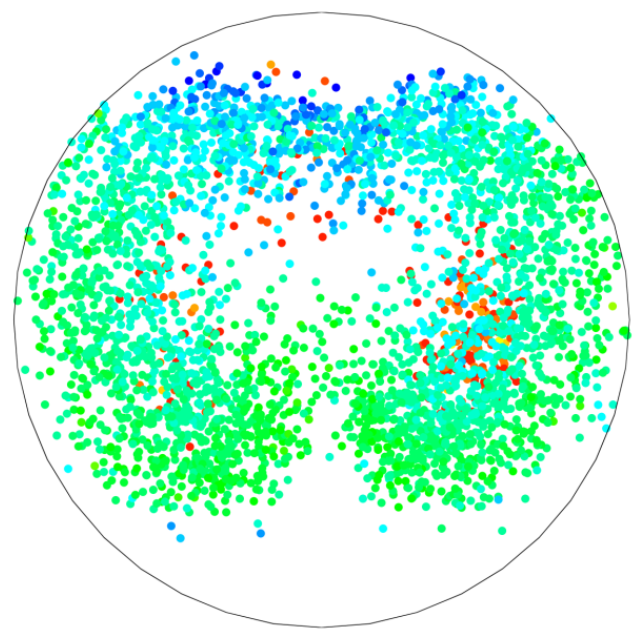

(c) $24 \% \mathrm{O}_{2}$

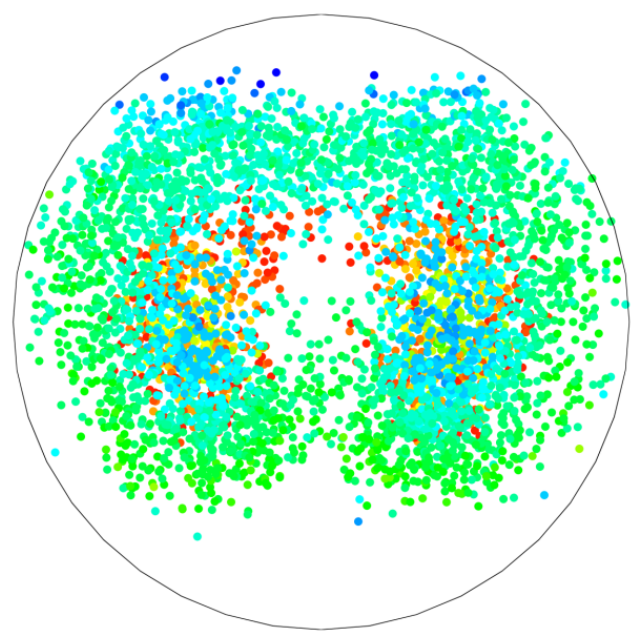

(b) $22 \% \mathrm{O}_{2}$

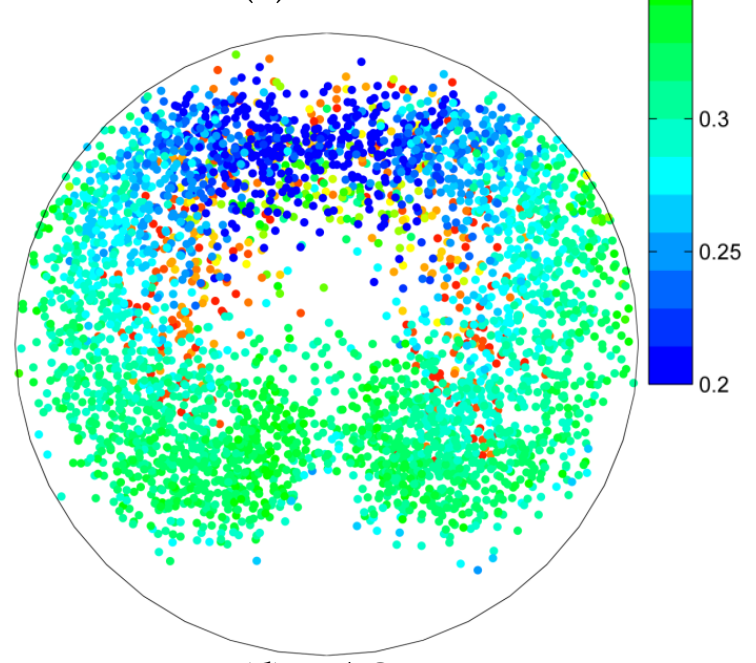

(d) $26 \% \mathrm{O}_{2}$

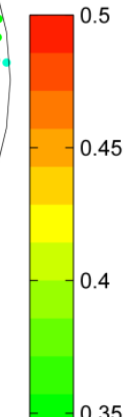

Figure 10. Migration of targeted area under targeted oxygen-enrichment.

Figure 12 shows the distribution of ${ }^{18} \mathrm{O}_{2}$ at the raceway outlet. The unreacted ${ }^{18} \mathrm{O}_{2}$ was mainly distributed over the upper area. However, there was no ${ }^{18} \mathrm{O}_{2}$ in the area where the targeted particles were distributed. The ${ }^{18} \mathrm{O}_{2}$ stream flowed into the original targeted area, while the new targeted area was produced. It was more difficult for newly targeted particles to obtain ${ }^{18} \mathrm{O}_{2}$. This further explained why the coal burnout slightly changed and the utilization of ${ }^{18} \mathrm{O}_{2}$ decreased with an increase in ${ }^{18} \mathrm{O}_{2}$. The combustion process was controlled by the diffusion of ${ }^{18} \mathrm{O}_{2}$. The coal burnout would be further increased by promoting the diffusion of ${ }^{18} \mathrm{O}_{2}$. 


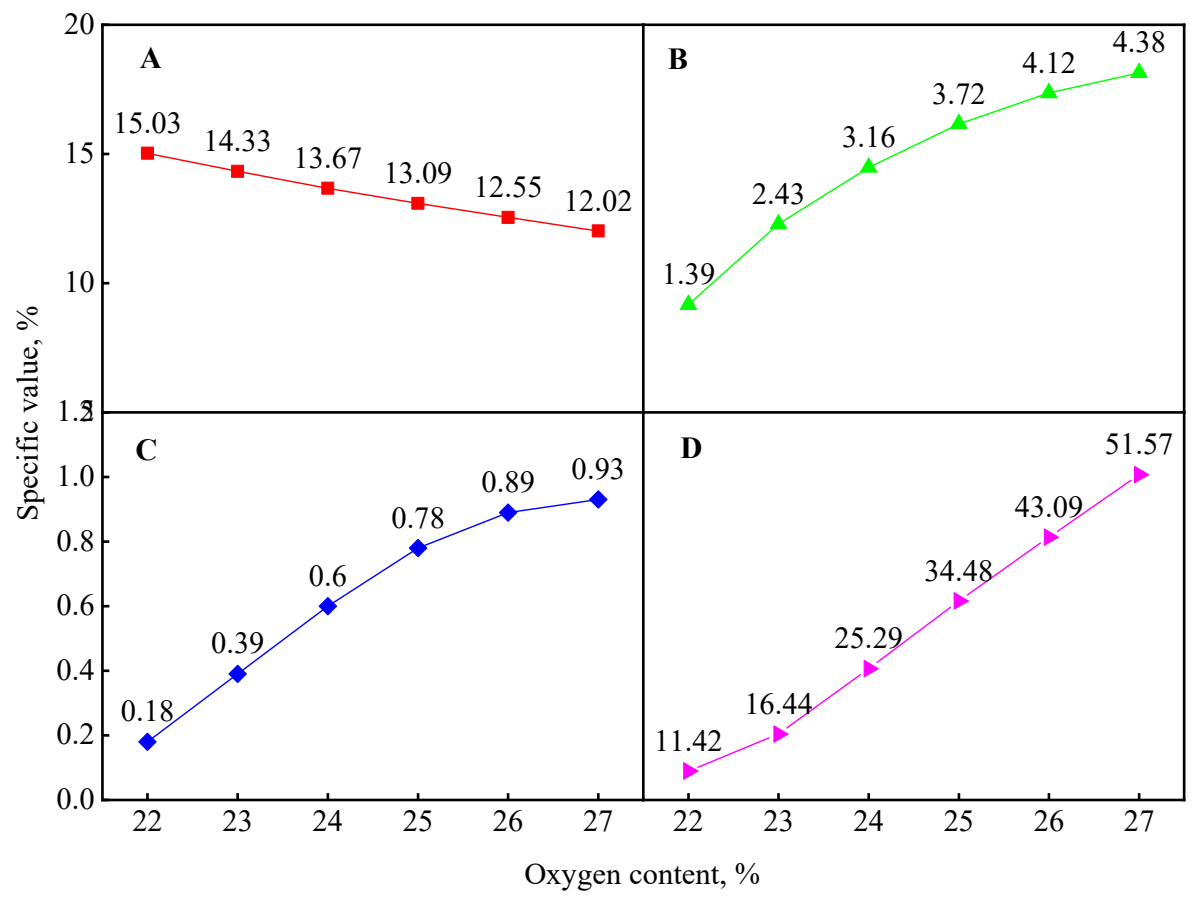

Figure 11. Different elements concentration, (A): $\mathrm{CO} / \mathrm{N}_{2},(\mathbf{B}): \mathrm{C}^{18} \mathrm{O} / \mathrm{N}_{2},(\mathbf{C}): \mathrm{C}^{18} \mathrm{OO} / \mathrm{N}_{2},(\mathbf{D}):{ }^{18} \mathrm{O}_{2}$ conversion ratio.
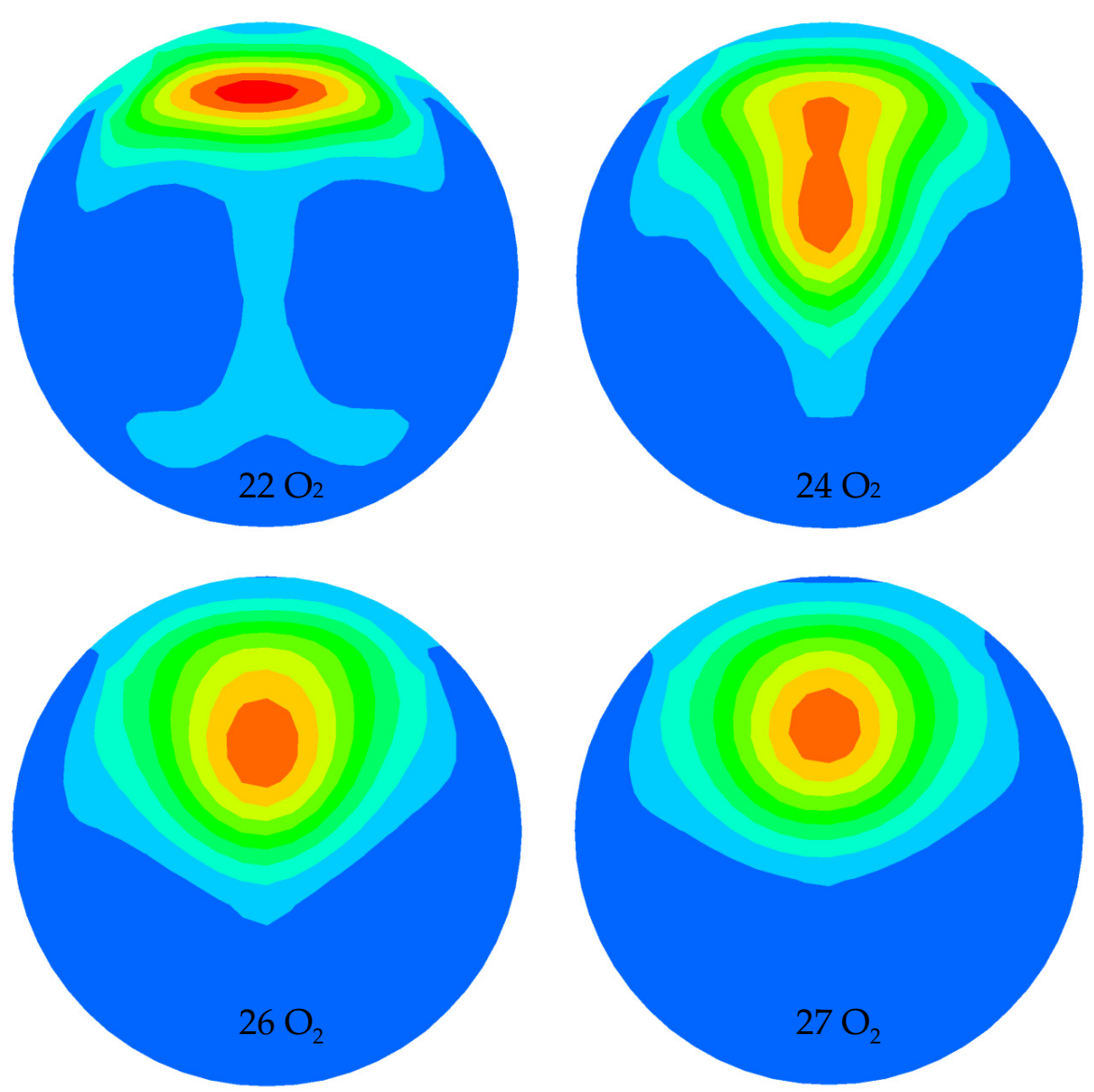

Figure 12. Distribution of ${ }^{18} \mathrm{O}_{2}$ at raceway outlet. 


\subsection{Effect of Coal Particles Temperature}

The cooling effect of room-temperature oxygen delayed the coal combustion process, and some coal particles did not have enough time to combust. Niu et al. [26] revealed that the pulverized coal preheating could promote early coal combustion. Because of this, the effect of coal particle temperature under targeted oxygen-enrichment on coal combustion was investigated. First, the effect of coal particle temperature at $21 \% \mathrm{O}_{2}$ on coal burnout was investigated, as shown in Figure 13. It shows that coal burnout slightly changed with an increase in the coal particle temperature. It means the coal burnout would not increase only by increasing coal particle temperature. The results show the limiting factor of coal combustion was oxygen concentration.

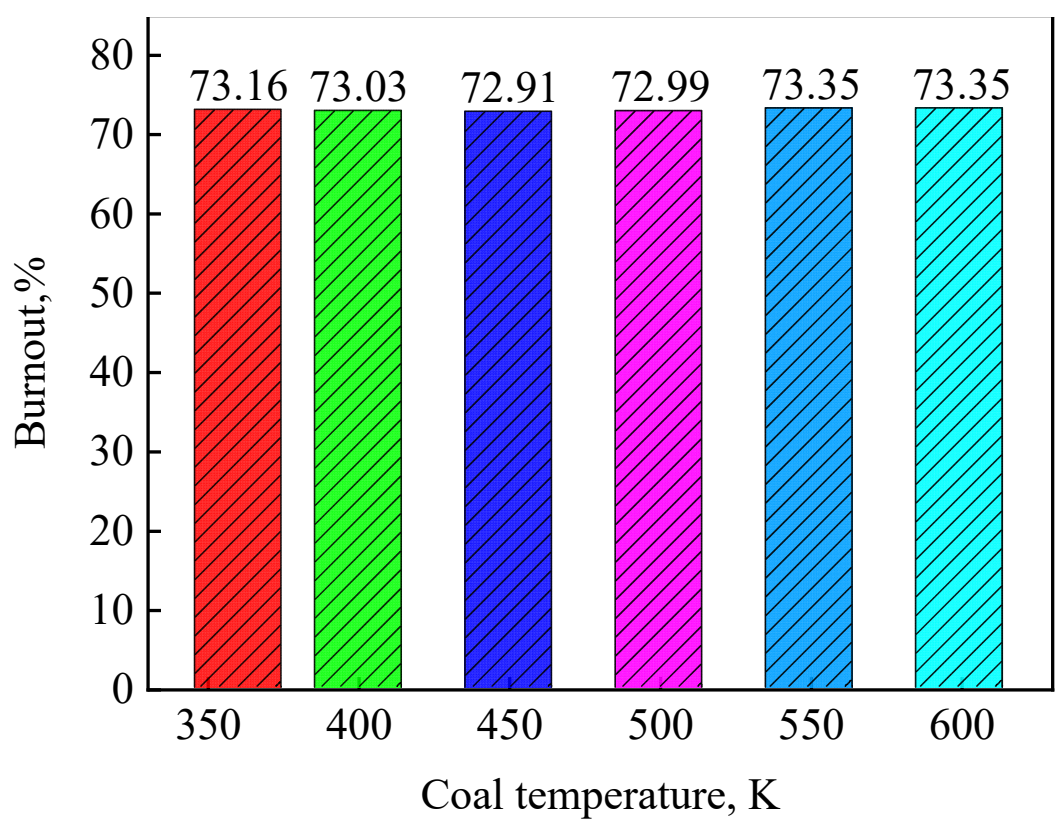

Figure 13. Effect of coal particles temperature on final coal burnout.

Figure 14 shows the effect of coal particle temperature on coal burnout under targeted oxygen-enrichment. In general, the coal burnout was further increased by increasing the coal particle temperature. When the coal particle temperature was $450 \mathrm{~K}$, the coal burnout was $84.16 \%$ at $1 \%$ oxygen enrichment, an increase of $11 \%$; the coal burnout was $88.05 \%$ at $4 \%$ oxygen enrichment, an increase of $14.89 \%$. The coal burnout continued to increase with an increase in the coal particle temperature. In particular, when the coal particle temperature was $600 \mathrm{~K}$, the coal burnout was $85.48 \%$ at $1 \%$ oxygen enrichment, an increase of $12.13 \%$; the coal burnout was $91.12 \%$ at $4 \%$ oxygen enrichment, an increase of $17.96 \%$. The results show the co-work of temperature and oxygen is more helpful for coal combustion.

To further understand the effect of coal particle temperature, the coal burnout at different positions was investigated, as shown in Figure 15. In general, the coal combustion process was enhanced, which became more obvious with an increase in the coal particle temperature. The hysteresis of the coal combustion process caused by the roomtemperature oxygen disappeared with an increase in the coal particle temperature. This is because the heat of coal particles makes up for the cooling effect of room-temperature oxygen. The coal particles had more time to combust, meaning the coal burnout quickly increased under sufficient oxygen. 


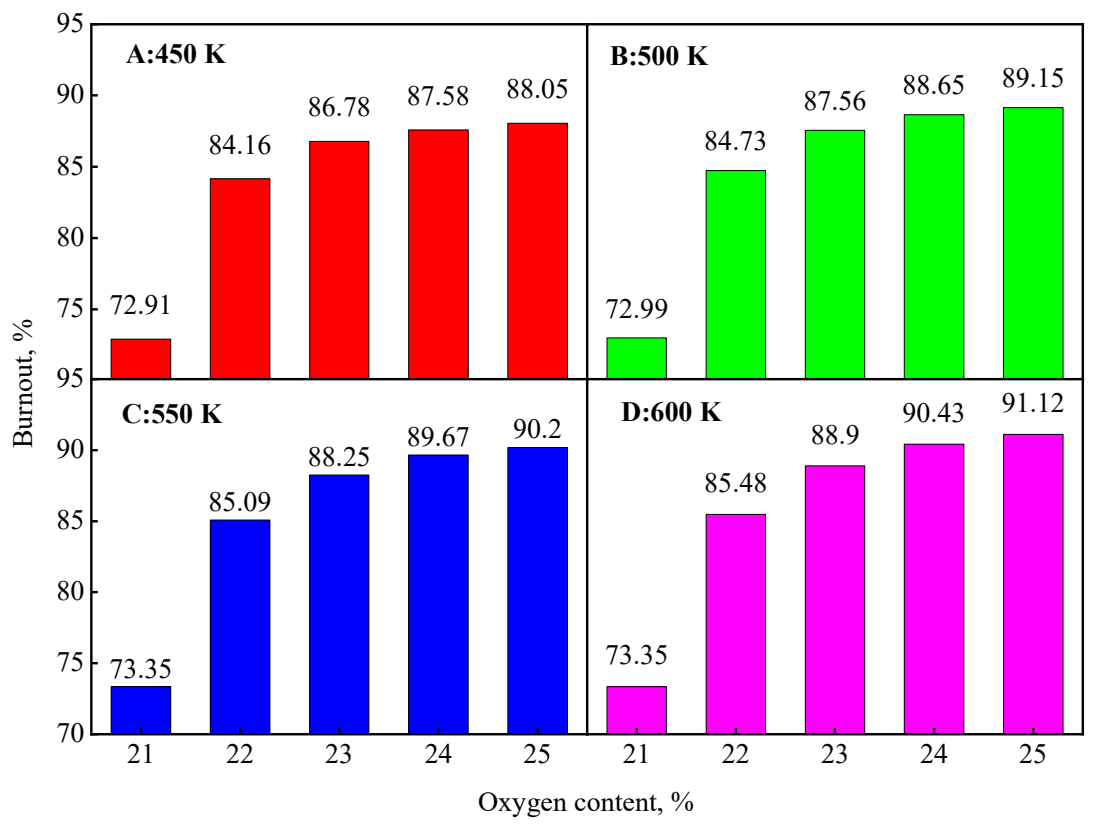

Figure 14. Final coal burnout under co-enhancement of heat and oxygen.

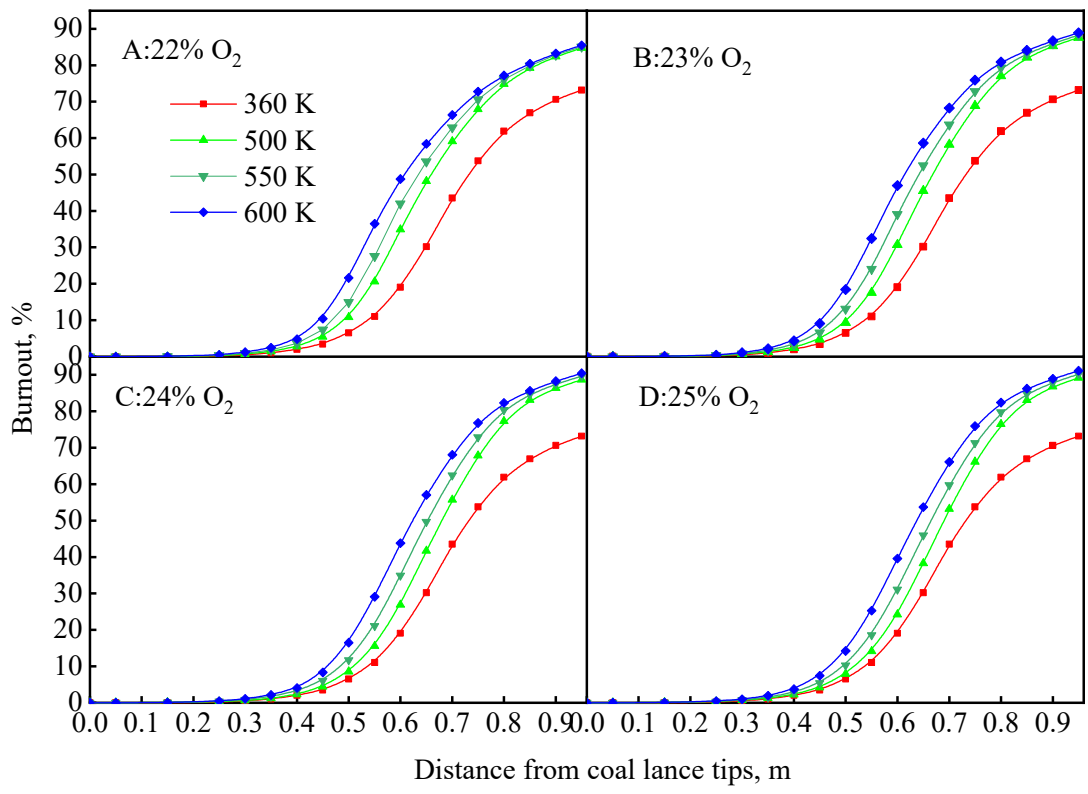

Figure 15. Coal burnout at different positions under co-enhancement of heat and oxygen.

\section{Conclusions}

In this study, the coal combustion characteristics in the raceway region of a blast furnace under targeted oxygen-enrichment were investigated. The main conclusions are as follows:

(1) The coal burnout increases significantly under targeted oxygen-enrichment. When the oxygen concentration is $22 \%$, the coal burnout has an increase of $10.59 \%$; when the oxygen concentration is $24 \%$, the coal burnout has an increase of $13.13 \%$, which is the maximum.

(2) The coal will increase only by increasing the oxygen concentration of the lowerburnout region. The oxygen concentration of the lower-burnout region is greatly increased under targeted oxygen-enrichment, while the coal particles are more dispersed under the effect of the oxygen stream. 
(3) When more oxygen is added, the increase of coal burnout is unclear. The coal burnout of $22 \% \mathrm{O}_{2}$ is $83.75 \%$, but the value of $23 \% \mathrm{O}_{2}$ is only $85.72 \%$. This is because the new lower-burnout region appears and is more dispersed under the effect of oxygen stream. This will be the main direction for future investigations to promote the dispersion of oxygen.

(4) The hysteresis of the coal combustion process caused by the room-temperature oxygen disappears and the coal burnout is further increased by increasing coal particle temperature. When the coal particle temperature was $600 \mathrm{~K}$, the coal burnout was $85.48 \%$ at $1 \%$ oxygen enrichment, an increase of $12.13 \%$; the coal burnout was $91.12 \%$ at $4 \%$ oxygen enrichment, an increase of $17.96 \%$.

Author Contributions: Investigation, Z.Z. and R.W.; data curation Q.Y.; writing—original draft preparation, Z.Z.; writing — review and editing, G.W. and C.M. All authors have read and agreed to the published version of the manuscript.

Funding: This research was funded by the Natural Science Foundation of Shandong Province, grant number ZR2019BEE077.

Data Availability Statement: The study did not report any data.

Acknowledgments: The authors gratefully acknowledge the financial support provided by the Natural Science Foundation of Shandong Province (No. ZR2019BEE077).

Conflicts of Interest: The authors declare no conflict of interest. The funders had no role in the design of the study; in the collection, analyses, or interpretation of data; in the writing of the manuscript, or in the decision to publish the results.

\section{References}

1. Geerdes, M.; van Laar, R.; Vaynshteyn, R. Low-cost hot metal: The future of blast furnace ironmaking. Iron Steel Technol. 2011, 8, $51-56$.

2. Chen, W.-H.; Du, S.-W.; Tsai, C.-H.; Wang, Z.-Y. Torrefied biomasses in a drop tube furnace to evaluate their utility in blast furnaces. Bioresour. Technol. 2012, 111, 433-438. [CrossRef] [PubMed]

3. Suopajarvi, H.; Pongrácz, E.; Fabritius, T. Bioreducer use in Finnish blast furnace ironmaking-Analysis of $\mathrm{CO}_{2}$ emission reduction potential and mitigation cost. Appl. Energy 2014, 124, 82-93. [CrossRef]

4. Ho, C.; Wu, S.; Zhu, H.; Yu, A.; Tsai, S. Experimental and numerical investigations of gouge formation related to blast furnace bur-den distribution. Miner. Eng. 2009, 22, 986-994. [CrossRef]

5. Wang, H.-T.; Zhao, W.; Chu, M.-S.; Feng, C.; Liu, Z.-G.; Tang, J. Current status and development trends of innovative blast furnace ironmaking technologies aimed to environmental harmony and operation intellectualization. J. Iron Steel Res. Int. 2017, 24, 751-769. [CrossRef]

6. Kushnir, D.; Hansen, T.; Vogl, V.; Ahman, M. Adopting hydrogen direct reduction for the Swedish steel industry: A technological innovation system (TIS) study. J. Clean. Prod. 2020, 242, 118185. [CrossRef]

7. Shen, Y.; Yu, A. Modelling of injecting a ternary coal blend into a model ironmaking blast furnace. Miner. Eng. 2016, 90, 89-95. [CrossRef]

8. Chen, W.-H.; Cheng, W.-Y.; Lu, K.-M.; Huang, Y.-P. An evaluation on improvement of pulverized biomass property for solid fuel through torrefaction. Appl. Energy 2011, 88, 3636-3644. [CrossRef]

9. An, X.-W.; Wang, J.-S.; Lan, R.-Z.; Han, Y.-H.; Xue, Q.-G. Softening and Melting Behavior of Mixed Burden for Oxygen Blast Furnace. J. Iron Steel Res. Int. 2013, 20, 11-16. [CrossRef]

10. Shen, Y.S.; Maldonado, D.; Guo, B.Y.; Yu, A.B.; Austin, P.; Zulli, P. Computational Fluid Dynamics Study of Pulverized Coal Combustion in Blast Furnace Raceway. Ind. Eng. Chem. Res. 2009, 48, 10314-10323. [CrossRef]

11. Liu, Y.; Shen, Y. CFD study of charcoal combustion in a simulated ironmaking blast furnace. Fuel Process. Technol. 2019, 191, 152-167. [CrossRef]

12. Du, S.-W.; Yeh, C.-P.; Chen, W.-H.; Tsai, C.-H.; Lucas, J.A. Burning characteristics of pulverized coal within blast furnace raceway at various injection operations and ways of oxygen enrichment. Fuel 2015, 143, 98-106. [CrossRef]

13. Yeh, C.-P.; Du, S.-W.; Tsai, C.-H.; Yang, R.-J. Numerical analysis of flow and combustion behavior in tuyere and raceway of blast furnace fueled with pulverized coal and recycled top gas. Energy 2012, 42, 233-240. [CrossRef]

14. Majeski, A.; Runstedtler, A.; D'Alessio, J.; MacFadyen, N. Injection of Pulverized Coal and Natural Gas into Blast Furnaces for Iron-making: Lance Positioning and Design. ISIJ Int. 2015, 55, 1377-1383. [CrossRef]

15. Wu, D.; Zhou, P.; Yan, H.; Shi, P.; Zhou, C.Q. Numerical investigation of the effects of size segregation on pulverized coal combus-tion in a blast furnace. Powder Technol. 2019, 342, 41-53. [CrossRef] 
16. Liu, Y.; Shen, Y. Three-dimensional modelling of charcoal combustion in an industrial scale blast furnace. Fuel 2019, $258,116088$. [CrossRef]

17. Hu, Z.; Liu, Y.; Xu, H.; Zhu, J.; Wu, S.; Shen, Y. Co-combustion of semicoke and coal in an industry ironmaking blast furnace: Lab experiments, model study and plant tests. Fuel Process. Technol. 2019, 196, 106165. [CrossRef]

18. Du, S.-W.; Chen, W.-H.; Lucas, J. Performances of pulverized coal injection in blowpipe and tuyere at various operational conditions. Energy Convers. Manage. 2007, 48, 2069-2076. [CrossRef]

19. Wu, D.; Zhou, P.; Zhou, C.Q. Evaluation of pulverized coal utilization in a blast furnace by numerical simulation and grey relation-al analysis. Appl. Energy 2019, 250, 1686-1695. [CrossRef]

20. Shen, Y.; Guo, B.; Yu, A.; Zulli, P. Model Study of the Effects of Coal Properties and Blast Conditions on Pulverized Coal Combustion. ISIJ Int. 2009, 49, 819-826. [CrossRef]

21. Murai, R.; Kashihara, Y.; Murao, A.; Sato, M. Convergent-divergent injection lance for the enhancement of combustion efficiency of pulverized coal at blast furnace. ISIJ Int. 2016, ISIJINT-2015-556. [CrossRef]

22. Zhou, Z.; Huo, H.; Wang, G.; Xue, Q.; She, X.; Wang, J. Effect of Oxygen-Coal Lance Configurations on Coal Combustion Behavior. Steel Res. Int. 2016, 88, 1600197. [CrossRef]

23. Shen, Y.; Shiozawa, T.; Austin, P.; Yu, A. Model study of the effect of bird's nest on transport phenomena in the raceway of an ironmaking blast furnace. Miner. Eng. 2014, 63, 91-99. [CrossRef]

24. Zhou, Z.; Xue, Q.; Li, C.; Wang, G.; She, X.; Wang, J. Coal flow and combustion characteristics under oxygen enrichment way of oxygencoal double lance. Appl. Therm. Eng. 2017, 123, 1096-1105. [CrossRef]

25. Wijayanta, A.T.; Alam, S.; Nakaso, K.; Fukai, J.; Kunitomo, K.; Shimizu, M. Combustibility of biochar injected into the raceway of a blast furnace. Fuel Process. Technol. 2014, 117, 53-59. [CrossRef]

26. Niu, Y.; Shang, T.; Zeng, J.; Wang, S.; Gong, Y.; Hui, S.E. Effect of Pulverized Coal Preheating on NO x Reduction during Combustion. Energy Fuels 2017, 31, 4436-4444. [CrossRef] 